\title{
A Comparative Study on the Responses by International Students towards the Teaching Strategies Used in an Australian University
}

\author{
Shen Chen, The University of Newcastle, NSW, Australia \\ Hing Wa Sit, The University of Newcastle, NSW, Australia
}

\begin{abstract}
This paper reports on a study conducted in the University of Newcastle, Australia, aiming to search for new knowledge about resolving teaching-learning problems due to the cultural differences rather than language deficiencies of overseas students, in particular, the South East Asian and the Middle Eastern postgraduate students in Australian universities. The study is generating important insights into the development of a new inclusive academic culture in Australian universities in order to meet the educational needs in a rapidly globalizing world.
\end{abstract}

Keywords: Teaching Strategies, International Education

\section{Introduction}

ПHE INTERNATIONALISATION OF higher education has been leading the global education industry since 1995 (Organisation for Economic Co-operation and Development-OECD, 2007). Due to economic reasons and the good reputation of its education system, Australia has become an exporter of higher education programs (Hewitt, 2002; Megarrity, 2007) and is ranked third after the USA and the UK in attracting international students (Novera, 2004). According to the Australian Bureau of Statistics (2007), 375,000 international students were enrolled in higher education institutions in 20042005. Among the international students undertaking higher education programs in Australia, a large percentage are from South East Asian and Middle Eastern countries. For instance, China has become the top market for international student enrolments at onshore Australian educational institutions in 2008 (AEI, 2008). The development of high quality of teaching is thus a major concern of the Australian government and of vital importance to Australian universities in order to meet the demands of the competitive global educational sector. .

International students have brought not only substantial economic benefits to Australian universities, but also new academic challenges to teaching and learning in their host universities ( $\mathrm{Su}, 2006)$. Since the beginning of this century, the research foci regarding international education have fallen within two major areas. One is concerned with learners, namely, the problems of their language proficiency and inefficient use of the target language when they study in a new country. Investigations on the principles of effective communication and pragmatics are examples of research in this area (Kim, 2001; Morita, 2004, Wang \& Shan, 2007). The other is concerned with teachers, namely, the study of intercultural competence and training. This kind of research has been conducted by Byram (2003), Gu (2005), Guilfoyle (2006) and Adrian-Taylor et al. (2007). However, international education is not simply de-

The International Journal of Learning

Volume 16, Number 9, 2009, http://www.Learning-Journal.com, ISSN 1447-9494

(c) Common Ground, Shen Chen, Hing Wa Sit, All Rights Reserved, Permissions:

cg-support@commongroundpublishing.com 
pendent on learners and teachers. More importantly, the interaction between students and teachers in a new cultural context should be considered in an integrative way rather than seen in isolation.

There is substantial literature on the internationalisation of higher education in the Australian context, but very little research into the cross-cultural training of students as part of Australian university curricula (Chen, 2008). Researchers have also paid less attention to unfamiliar learning environments causing cultural conflict between teaching strategies and international students' learning styles as derived from cultural values in their home countries.

The research reported by this paper is aiming to investigate international students' responses and perspectives towards the major teaching strategies (Killen, 2007) commonly used in Australian universities in contrast with those of their home countries and how they make academic adjustment in a new cultural environment of learning. Obviously, the outcome of the investigation is of significance in exploring the validity and efficacy of various teaching strategies which are viewed differently through the eyes of international students. This paper reports the findings of this research in order to promote quality teaching in the context of increasing student diversity in Australian universities.

\section{Method}

The research was conducted in the University of Newcastle, Australia which has witnessed a substantial increase of international students, coming mainly from South East Asian and Middle Eastern countries. In order to identify the different responses from these two cultural groups, the methods used for this research included both quantitative survey and intensive qualitative data-collection. The former was used to identify their preference to the seven teaching strategies commonly used in Australian universities. These strategies are (1) direct instruction; (2) discussion; (3) group work; (4) cooperative learning; (5) problem solving; (6) student research; and (7) performance activities. They are effective teaching methods commonly used in Australian universities to enhance the learning of the local Australian students (Dunkin \& Biddle, 1974; Wittrock, 1986; Good \& Brophy, 1991; Killen, 2007; Westwood, 2008). In order to evaluate their validity to international students and to collect feedback from them, five scales were used to assess each teaching strategy ranging from strongly negative (1) to strongly positive (5). The statistics demonstrated the mean score for each strategy from the two major cultural groups of international students in order to enable valid comparison. The South East Asian group (SA) consisted of 10 students, who came from Indonesia (2), Thailand (2), The Philippines (1), Korea (1), Japan (1) and China (3). The Middle Eastern (ME) group included 10 students, from Saudi Arabia (6), Iran (2) and Kuwait (2).

The second stage was the intensive qualitative data collection. In order to achieve the depth and breadth of investigation and to fully elaborate the specific phenomenon of cultural conflicts the data were collected from both cultural groups (SA and ME). Since they were familiar with the teaching strategies used in their home countries during their undergraduate study, their responses to the new teaching strategies were often based their previous experience, which might explain the reasons why their preference were varied from one group to the other. The in-depth interview, a very useful technique for collecting qualitative data, helped two research assistants, who were international students themselves, to engage with the detailed and specific information of the data so as to "get close to an individual's per- 
spective" (Kayrooz \& Trevitt, 2005, p.110), and "understand people's experience and to suggest useful explanations or interpretations" (Wang \& Shan, 2007, p. 5). The interviews were semi-structured with open-ended questions due to their greater flexibility (Minichiello et al., 1995) and potential to encourage interviewees to articulate personal perspectives (Flick, 2002). This method provided flexibility for the interviewees to share their learning experiences freely as well as offering opportunities for the interviewer to gain an understanding of responses to the seven key teaching strategies mentioned previously and identify any cultural gaps or cultural conflicts between teaching and learning.

The twenty participants were interviewed individually for approximately thirty to forty minutes. The interviews were all digitally recorded and then transcribed verbatim. In order to ensure validity and reliability, methods such as feedback and member checks were employed. The former was very useful for identifying validity threats, any bias and assumptions and keeping the research on right track. The latter was the single most important way of ruling out the misinterpretations of the meaning of participants' comments and perspectives on proceedings (Maxwell, 1996, p. 94). The interviews were used as a guideline to elicit interviewees' responses to/perceptions of the seven major commonly used teaching strategies and to understand their process of academic adjustment to the culturally new learning environment.

\section{Data Analysis}

Due to the limited number of participants, the quantitative survey did not provide significant data about differences in terms of gender, age or socio-economic background, but did demonstrate the major gaps of preference between the two cultural groups. The average scores given to each teaching strategy by both groups were calculated and compared. As to the initial analysis of qualitative data, all the transcripts were loaded into NVivo7 (N7) software which organized a database for all the textural data collected to be used at a later stage. In terms of the initial coding, the seven teaching strategies were used as main indicators for this study. Each interview was entered as a separate text file. The analysis was assisted by the matrix operation in N7 which helped not only categorize and conceptualize data effectively, but also created "nodes" to mark relevant concepts and topics in text documents that could be searched and analyzed (Walsh, 2003). The analysis assisted in identifying connections between specific themes as well as gaps and discrepancies. In addition, the information was systematically arranged and sorted by theme and concept, thus preliminary categories were formed. Eventually the original data was compared across each category.

\section{Findings}

The following table reflects the differences between the teaching strategies preferred by the two cultural groups. The numbers are the means of the total scores ranging from strong negative response to strong positive response (1-5). The statistical indication is consistent with the qualitative data showing different views from the two identified groups. Both quantitative and qualitative data are given below: 


\begin{tabular}{|l|l|l|l|}
\hline Teaching Strategies & $\begin{array}{l}\text { South-East Asian } \\
\text { Group }\end{array}$ & $\begin{array}{l}\text { Middle East } \\
\text { Group }\end{array}$ & Differences \\
\hline Direct instruction & 4.3 & 3.7 & 0.6 \\
\hline Discussion & 3.0 & 4.1 & 1.1 \\
\hline Group work & 2.8 & 3.2 & 0.4 \\
\hline Cooperative learning & 3.2 & 3.2 & 0 \\
\hline Problem solving & 3.2 & 3.5 & 0.3 \\
\hline Student research & 4.0 & 4.1 & 0.1 \\
\hline Performance activities & 3.6 & 2.8 & 0.8 \\
\hline
\end{tabular}

(1) Direct Instruction: Both the South East Asian group and the Middle East group had positive responses to this most commonly used teaching strategy, namely, Direct Instruction, normally presented in the form of lecture which features teacher-centered, one-way communication. Here are two citations from two students in SE group and ME group respectively:

A SEA student: I like this strategy, yeah, because it can give you very clear idea about what you are going to do next, and you don't need to spend a lot of time yourself to figure out: Oh, what's the lecturer wants us to do?

A ME student: like a lecture? No, I don't like it so much. ... You just listen, but not always in our interests. It is just like I am sitting there and hearing, and then going out. If I have questions, if I want to discuss them, I can't...

The South East Asian students liked Direct Instruction more than the Middle Eastern students did because the former had got used to participating in lectures with a large number of students while the latter preferred to have opportunities to express their own views in addition to listening to their lecturers talk.

(2) Discussion: The above table shows a significant gap (1.1) between the two cultural groups. The South East Asian students preferred to be silent in any kind of discussion. Their response to Discussion was neutral (3.0). On the other hand, the Middle East students were in favor of Discussion. Here are two examples:

A SEA student: ...As a matter of fact, I don't adapt it very much and won't say I like it or dislike it, because seldom did we have discussions in China. Whereas, uh, you would be asked to discuss suddenly here, and sometimes, you would even feel that there was actually nothing to discuss for those questions...

A ME student: ...That's very good. Because, the point we shared is not only used by the teacher, but by all of the group, and the teacher is one of them. So this way, I mean, it depends on the teacher, if he urges all of the students to participate. Some of them might be shy, some of them had really good competence but they are shy...

(3) Group Work: As to this teaching strategy, the South East Asian group responded negatively since they prefer to work individually. On the contrast, the Middle East group provided a positive response in general. This point was explicitly expressed by the remarks from two students belonging to the two cultural groups respectively. Their comments voiced the typ- 
ical common concern about the effectiveness of this teaching strategy, although Group Work is frequently used by teachers in Australia from the primary up to the tertiary level

A SEA student: ...In fact, "Group work" has its advantages, but on the other hand, it also has its disadvantages. Different people would have different goals when working together. As a result, I do not like "Group work"...

A ME student: ...I really like it. But depends on what kind of members we have in a group, because normally I don't like it when I have, let's see, like lazy...group members, because the members they just sit to listen to others and they don't want to do anything...

(4) Cooperative Learning: Working together by dividing a task is new to the both cultural groups. They were not sure about if this would work well since the lecturers in their home countries rarely use this teaching strategy. It is interesting to see that two groups responded differently to this teaching strategy. The following comments from each group were an example of difference:

A SEA student: ...It's actually good, because it not only stress everyone's effort to the group work, but it also requires working cooperatively rather than one's working alone. Let's assume that if 4 students did an assignment and I was thinking about the problem, then I might have considered about it wrongly? In this case, you might have been doing incorrectly if no body helped and pointed where the mistake might be...

A ME student: ...I do not like it. I prefer to do my work alone. And even the teacher, she can know each student, what his ability is, she sees his own work, but in a group, how do you know this information is from all of them, is not from only one...

(5) Problem Solving: In spite of the fact that this teaching strategy was also unfamiliar to the both groups, both groups held a more positive attitude towards this teaching strategy in comparison with Cooperative Learning. This attitude can be seen clearly from the in-depth interviews:

A SEA student: ...Mm...because it seems that seldom have we experienced such kind of strategy in class, so far as less. It was only used in Australia. It would be more effective if the teacher assigns the task ahead and asks student prepare it well...

A ME student: ...I haven't seen that in my country. But I have seen it here. I think it is really good because I found the knowledge that I get myself in the web, I understand it and I don't forget it easily...

(6) Student Research: This teaching strategy gives students an opportunity to work by themselves through a research topic or research project. Students are asked to work independently although the teachers provide regular supervisions. It is noticeable that it received positive responses from both cultural groups. Students also provided the reasons why they like it. These comments were selected from the qualitative data:

A SEA student: ...I like it. I think it is interesting. Because I once was a teacher, I think if I were a student, I like this strategy too. At least make the students do some preparation for attending class, which is a pleasant process for student as he or she is searching for the knowledge by himself or herself... 
A ME student: ...You would learn not only the specific information about the topic. May be when I research about any topic, I would learn more things or specific things...

(7) Performance Activities: This teaching strategy was praised and criticized by the two cultural groups who held opposing views. The following quotations represent the students' general feelings about this teaching strategy:

A SEA student: ...I feel it is a very good teaching strategy, because I had memorable feeling about it before. If appropriate performance actives were employed, they would feel more interesting maintain sober, and have a stronger sense of participation...

A ME student: ...I don't know, I am not that comfortable to do "Role Play", because for me, presentations are difficult for me always, they are. I am not...really comfortable to be in front of others, talking to people...

\section{Discussion}

The findings from the quantitative and qualitative investigations have revealed a number of issues which can be further explored from theoretical perspectives. Firstly, from the international students' viewpoint, the responses raised the issue of international students' understanding of the role of interaction between teaching and learning in the universities of the host country, Australia. Secondly, in terms of adjustment to the new teaching strategies, there is an issue of cultural conflict due to the students' cultural values from their home countries.

In the first place, the seven teaching strategies can be broadly categorized into two contrasting approaches: teacher-centred approach and learner-centred approach (Killen, 2007; Prosser \& Trigwell, 2006). Among those seven teaching strategies, Direct Instruction is more teacher-focused and concerned with effective transmission of information and skills from teacher to student, while other more student-focused approaches are more concerned with bringing about deeper conceptual understanding and change in students (Westwood, 2008). The responses from all interviewees across both cultural groups showed that it is necessary and effective to learn by using teacher-centred approach like Direct Instruction. They preferred to directly obtain obvious and clear knowledge from the teacher and expected the teacher to teach systematically and structure knowledge step-by-step in class to make them understand what was taught. The most important reason, according to the interview, is that this strategy was commonly used in their home countries; hence they had never questioned the value of Direct Instruction. On the other hand, the participants had mixed views regarding the more learner-centred approaches. Generally speaking, all interviewees found strategies such as Group Work and Cooperative Learning helpful, especially when doing assignments. However, strategies like Discussion and Problem Solving were not as popular as the others. This tendency shows that the roles they played in their previous classrooms, in their home countries, have been challenged, creating a problem of changing roles in the new learning environment. In the new cultural context of Australia they became confused about their role in the interaction between teaching and learning, since the teacherstudent relations in their home countries always required students to play a less active role, passively receiving knowledge rather than challenging teachers, who were regarded as the source of knowledge. 
The demanding situation in host universities which forced the international students to reset their roles naturally lead to the second concern, namely the cultural conflict of teaching and learning due to their previous cultural values. Hence, it is important to recognize international students' different assumptions and attitudes towards knowledge and learning styles as these approaches are "products of their respective cultures and their individual experiences of education within their countries" (Wang \& Shan, 2007, p. 11). The two largest gaps between the South East Asian group and the Middle Eastern group confirm the significance of cultural values in determining attitudes towards student centred approaches. One gap was identified in responses to Discussion, upon which the South East Asian students, who are often influenced by Confucian ideology, maintained a neutral (3.0) stance. These students tended to be silent in discussion and did not ask questions, which is consistent with Vardanega et al.'s (2003) observation that many East Asian students fear that asking questions openly in the class might be seen as stupid or exposing of ignorance. They seem to prefer individual work rather than working in groups (Woodrow \& Sham, 2001). However, the Middle Eastern students demonstrated a positive response towards Discussion (4.1) although traditional Islamic values also emphasize respect of teachers. By contrast, the South East Asian students favoured Performance Activities (3.6) since Performance Activities are often part of the extracurriculum activities of schools in their home countries. Conversely, Islamic tradition may see Performance Activities as entertainment rather than a form of learning. This might be the reason why the Middle Eastern students gave very low scores for Performance Activities (2.8). They found it difficult to adjust themselves to this unfamiliar teaching strategy because of their pre-existing cultural values.

The reluctance of accepting student-centered approaches to teaching and the differing attitudes towards each teaching strategy provide empirical evidence against two assumptions often held by university teachers in the host country. The first is that when international students pursue their education in Australian universities, there is a natural expectation that they should follow the principle of "when in Rome, do as the Romans". In other words, if students wish to study in Australia, they must adopt and adhere to Australian methodologies. Secondly, international students are often seen as a single, cohesive body in comparison to native students, so it is often assumed they can be treated homogenously regardless of cultural diversity. Many university teachers in Australia wrongly presume that any student from the international cohort can be taught equally effectively by any single teaching method.

As Kramsch (1993) criticised that the dichotomy of "teacher-centered approach" and "student-centered approach" can be misleading in terms of teachers' and students' roles, therefore a "learning-centered approach" may be a more acceptable notion, since both teachers and students focus on the learning process and aim to achieve the best learning outcome. The international students' learning styles were associated with the educational philosophies valued in their home countries. For instance, Chinese students' perception of a teacher's role is influenced by Confucian educational philosophy. Unless Australian university teachers explain the purposes and values of other six teaching strategies except Direct Instruction, Chinese students will not automatically understand why they are required to play an active role in learning. According to Kramsch's theory (1993), the traditional view of "adjustment" by international students should be replaced by a new notion of "the third place" which refers to a state of change in cultural value through interacting with new cultures. In other words, by studying in Australian universities, Chinese students will make a progress towards a state of neither abandoning their educational beliefs as influenced by Confucius 
nor completely adopting the Australian way of learning. In this sense, Australian university teachers should be aware that the process of reaching "the third place" will not take place overnight. Interpretation of various teaching strategies and guidance leading to full comprehension is necessary if teachers have equally high expectations of learning outcomes to be achieved by local and international students.

In addition, according to Valimma (1998), international students - whatever their cultural origins, encounter two new cultural frames, namely, disciplinary-based cultures and institutionally-based cultures. In addition, they also face a difference between their home cultures and new target cultures. (i.e. those of the country where they are undertaking study). Therefore it is their university teachers' responsibility not only to familiarize the students with disciplinary-based cultures and institutionally-based cultures, but also to help students to make their adjustment in new target culture of teaching and learning. In handling disciplinary-based cultures and institutionally-based cultures, the university teachers are confident and competent because their major task is to make international students understand and become familiar with the new learning environment. However, resolving the conflicts between students' home cultures and the new target culture is beyond the university teachers' control since the home cultures vary from one country to another, although the teachers may be experts of the target culture which the international students want to learn. To overcome this problem, it seems that university teachers have to rely on modification towards a balance of various teaching strategies and therefore to meet the needs of both South East Asian students and Middle Eastern students since depending only on a few favorable teaching strategies may advantage one group whilst disadvantaging the other. In reality, most Australian universities are culturally diversifying as the local students mix with international students from around the world. Guilfoyle (2006) suggests that in creating a supportive teaching-learning environment for positive experiences of international students, it is necessary to explore the interaction between teachers and students in the light of socio-cultural consideration. Therefore it is time to rethink existing teaching strategies and to search for new ones to accommodate students of different cultural backgrounds. This is both an urgent issue and a challenging task which must be faced by all Australian universities.

\section{Conclusion}

The research reported in this paper is based on a single case study of one Australian university but represents the common concern of all universities in Australia, namely, how to make a pedagogical change to meet the needs of increasing numbers of international students from different regions. A number of conclusions can be drawn from this investigation. Firstly, the outcome of the study on international students' responses to teaching strategies shows that Australian university teachers should no longer rely solely upon use of previously preferred teaching strategies once the classroom becomes internationalized. The validity and efficacy of various teaching strategies depend upon the learning styles of international students with different cultural values. It is not realistic to rely on a monocultural or culturally neutral approach. A dynamic approach of interaction between teaching and learning must thus be considered. Secondly, taking various ethnic groups into consideration, the Australian teachers' selection of various teaching strategies should be balanced to meet the needs of diverse learners. The modification towards methodological balance should be made based on investigation of students' native educational cultures. This is an arduous research task 
since it is difficult to identify and isolate broad cultural characteristics from the individual differences. There is a strong risk of creating stereotypes of various ethnic groups which would be harmful to teacher-learner relationships. The study conducted in this research is very limited since the South East Asian group of subjects came from various countries, as did the subjects from the Middle Eastern group. Finally, cohesive interaction of teaching and learning depends on compromise by both Australian university teachers and international students. Needless to say, university teachers and international students with different cultural backgrounds have various perspectives derived from their own cultural values, beliefs, and educational philosophies, but this diversity should not hinder both sides learning successfully through interaction with each other.

\section{References}

Adrian-Taylor, S., Noels, K. \& Tischler, K. (2007). Conflict between international graduate students and faculty supervisor: Toward effective conflict prevention and management strategies. Journal of Studies in International Education, 11 (1), pp.99-117.

AEI. (2008). AEI International Student Data YTD July 2008. Australian Government, Australia. Retrieve 2 November, 2008, from http://aei.gov.au/AEI/MIP/Activities/08Activity08.htm

Australian Beureau of Statistics. (2007). Australian social trends 2007. International students in Australia. Retried 18 May, 2008 from http://www.abs.gov.au/Ausstats/@nfs.

Byram, M. (2003). "On being 'bicultural' and 'intercultural'.” In Alerd, G., Byram, M., \& Fleming, M. (Ed.). Intercultural experience and education (pp. 56-66). Clevedon: Multilingual Matters Ltd.

Chen, S. (2008) “Chinese Research Students' Adjustment to Australian Learning Environment.” The International Journal of Learning, Volume 15, Number 1, pp43-49.

Dunkin, M. J. \& Biddle, B. J. (1974). The study of teaching. Sydney: Holt, Rinehart and Winston.

Flick, U. (2002). An introduction to qualitative research. London: Sage.

Good, T. \& Brophy, J. (1991). Looking in classroom (5th ed.). New York: Harper Collins.

$\mathrm{Gu}, \mathrm{Q}$. (2005). "Perception of the perception gulf-An investigation into the British education development projects in China." In intercultural journal of educational development. 25, pp. 287304.

Guifoyle, A. (2006). Peer, family, community, supervisor and governance: A review of key sites for supporting international postgraduate students' transitional learning experiences. Teaching and Learning Forum. Accessed 30 July. Available from:http//www.lsn.

Hewitt, M. R. (2002, 7-9 July 2002). The internationalisation of accounting programs of Australian universities: Observing cultural influences on learning. Paper presented at 2002 AAANZ Annual Conference. Perth, Western Australia. Retrieved 3 November, 2008, from http://www.aaanz.org/web2002/accepted\%20 papers/hewittm.pdf

Kayrooz, C., \& Trevitt, C. (2005). Research in organizations and communities: Tales from the real world. Crows Nest, NSW: Allen \& Unwin.

Killen, R. (2007). Effective teaching strategies: lessons from research and practice (4th ed.). South Melbourne, Vic.: Thomson Social Science Press.

Kim, Y.Y. (2001). Becoming intercultural. An integrative theory of communication and cross-cultural adaptation. Thousand Oakes, CA: Sage.

Kramsch, C. (1993) Context and Culture in Language Teaching. Oxford: Oxford University Press.

Maxwell, J. A. (1996). Qualitative research design. An interactive approach, Thousand Oaks, Sage, pp. 86-98.

Megarrity, L. (2007). A highly-regulated 'free market': Commonwealth policies on private overseas students from 1974 to 2005. Australian Journal of Education, 51, pp39-53. 
Minichiello, V., Aroni, R., Timewell, E., \& Alexander, L. (1995). In-depth interviewing (2nd ed). Longman, 61- 75 .

Morita, N. (2004). "Negotiating participation and identity in second language academic communities." In TESOL Quarterly, 38/4, pp. 573-603.

Novera, I. A. (2004). Indonesian postgraduate students studying in Australia: An examination of their academic, social and cultural experiences. International Education Journal, 5 (4), 475-487.

OECD. (2007). Education at a glance. OECD indicators 2007. Paris: Author.

Prosser, M., \& Trigwell, K. (2006). Confirmatory factor analysis of the 'Approaches to teaching inventory'. British Journal of Educational Psychology, 76 (2), 405-419.

$\mathrm{Su}$, S. J. (2006). “Give me wings to fly-What can be done better to smooth Chinese students' academic adaptation experience at one Australian university?” In Giddings, R(Ed.), 17th International Education Conference Sydney 06. Australia: International Education Association Inc (ISANA).

Valimma, J. (1998) “Culture and Identity in Higher Education Research" in Higher Education, 36, pp119-138.

Vardanega, L., Hatcher, D., \& Crombie, K. (2003). Sustaining quality learning environmental scientists. Paper presented at the16th ODLAA Biennial Forum Conference Proceedings (ON CD), ODLAA, 1-10.

Walsh, M. (2003). Teaching qualitative analysis using QSR NVivo. The Qualitative Report, 8(2), 251256. Retrieved 16 Oct, 2008, from http://www.nova.edu/ssss/QR/QR8-2/Walsh.pdf

Wang, T., \& Shan, X. J. (2007). A qualitative study on Chinese postgraduate students' learning experiences in Australia. Higher Education Research \& Development, 18, pp.1-19.

Westwood, P. (2008). What teachers need to know about teaching methods. Camberwell, Vic.: ACER Press.

Wittrock, M. C. (1986).Handbook of research on teaching (3rd ed.). New York: Macmillian.

Woodrow, D. \& Sham, S. (2001). Chinese pupils and their learning styles. Race, Ethnicity and Education, 4 (4), 377-394.

\section{About the Authors}

\section{Shen Chen}

A/Prof. Shen Chen is currently teaching and supervising post-graduate students in the School of Education, the University of Newcastle, Australia. His research interest includes International Education, Second and Foreign Language Teaching and Intercultural Communication.

\section{Hing Wa Sit}

Hing Wa Sit is a Ph.D student in the School of Education, the University of Newcastle. She holds an Australian degree of Master of Educational Studies and worked as research associate in the University of Hong Kong in 2007. She has been a research assistant in Australia since she came to Newcastle. Hing Wa Sit has been working on a number of research projects on Chinese and English language education and published several academic papers in international journals. Her research interests include international education, second language education, cross cultural studies and teaching strategy use for advanced English learners. 